\title{
A peptide mimetic of the mycobacterial mannosylated lipoarabinomannan: characterization and potential applications
}

Correspondence

Ayelet Barenholz

ayeletba@ekmd.huji.ac.il

Received 29 August 2006

Accepted 5 January 2007

\author{
Ayelet Barenholz, ${ }^{1}$ Avi-Hai Hovav, ${ }^{1} \dagger$ Yolanta Fishman, ${ }^{1}$ Galia Rahav, ${ }^{2}$ \\ Jonathan M. Gershoni ${ }^{3}$ and Hervé Bercovier ${ }^{1}$
${ }^{1}$ Department of Clinical Microbiology, The Faculty of Medicine of the Hebrew University of Jerusalem, Jerusalem, Israel
${ }^{2}$ Unit of Infectious Diseases, Sheba Medical Center, Ramat Gan, Israel
${ }^{3}$ Department of Cell Research and Immunology, George S. Wise Faculty of Life Sciences, Tel Aviv University, Tel Aviv, Israel

\begin{abstract}
Mannosylated lipoarabinomannan (ManLAM), a complex lipoglycan, is a major component of Mycobacterium tuberculosis, the agent of tuberculosis (TB), and is an antigen used for serological diagnosis of TB. Screening random phage-display peptide libraries with anti-ManLAM mAb CS40 for peptide epitope mimics (mimotopes) led to the isolation of a panel of peptides. One of these peptides (B11) was characterized as a ManLAM mimotope: it bound the anti-ManLAM CS40 mAb and competed with ManLAM for antibody binding. Mice immunized with keyhole limpet haemocyanin-conjugated B11 peptide in a proper adjuvant developed antibodies that recognized ManLAM. Competition experiments demonstrated that the B11 peptide inhibited binding of $\mathrm{mAb}$ CS40 to ManLAM in a concentration-dependent manner. The data indicated that the affinity of CS40 mAb to B11 $\left(K_{\mathrm{D}} 1.33 \times 10^{-8}\right)$ is higher than its affinity to ManLAM $\left(K_{\mathrm{D}}\right.$ $\left.3.00 \times 10^{-7}\right)$. The sera of TB patients, as well as the sera of mice experimentally infected with $M$. tuberculosis, contained significant levels of antibodies that recognized both the B11 peptide and ManLAM. The specificity and sensitivity of the ELISA B11-based test were similar to those of the ELISA ManLAM-based test, indicating that the B11 antigen could be a good substitute for ManLAM serology for the diagnosis of TB.
\end{abstract}

\section{INTRODUCTION}

Carbohydrate antigens of micro-organisms are targets of the immune system in a variety of infectious diseases and as such have been suggested as candidates for diagnosis and immunization. A major obstacle in using carbohydrates as antigens is the difficulty involved in obtaining or synthesizing complex carbohydrate ligands. A possible alternative to the use of carbohydrates would be the development of protein or peptide mimics that are specifically recognized by anti-carbohydrate antibodies (Abs) and can thus serve as surrogate diagnostic markers in serological tests. Peptides are well defined and easier to synthesize than complex microbial polysaccharides.

tPresent address: Division of Viral Pathogenesis, Department of Medicine, Beth Israel Deaconess Medical Center, Harvard Medical School, Boston, MA 02215, USA.

Abbreviations: i.p., intraperitoneally; $\mathrm{KLH}$, keyhole limpet haemocyanin; ManLAM, mannosylated lipoarabinomannan; MPL-TDM, monophosphoryl lipid A+trehalose dimycolate; s.c., subcutaneously; SPR, surface plasmon resonance; TB, tuberculosis.
Combinatorial phage-display peptide libraries have been used for identifying peptide epitope mimics (mimotopes) of microbial polysaccharides (Shin et al., 2002). An additional application of these peptidomimetics could be as components in a vaccine in which the peptides would elicit an immune response that could cross-react with the corresponding sugar targets of the pathogen (Tang et al., 2003).

Mannosylated lipoarabinomannan (ManLAM) is a lipoglycan, a polysaccharide with a phosphatidyl-myo-inositol anchor. ManLAM is a major cell-surface component of Mycobacterium tuberculosis, the agent of tuberculosis (TB) (Chatterjee et al., 1992). The polysaccharide ManLAM has diverse biological activities in the development of mycobacterial pathogenesis and in the interaction with macrophages in vitro that are different from the biological actions induced by other lipoarabinomannans present in nonpathogenic mycobacteria (Briken et al., 2004). ManLAM binds to macrophages via mannose-binding receptors such as the mannose receptor and DC-SIGN, and immunomodulates various cytokines and nitric oxide secretion 
(Prinzis et al., 1993; Tailleux et al., 2003). ManLAM is a large complex molecule that is difficult to analyse and elucidate which of its components are responsible for the specific activities of the molecule functions. Mimotopes of specific epitopes might be good candidates for addressing two major issues in TB: efficient diagnosis (Antunes et al., 2002; Ciesielski, 1995) and effective vaccination (CastanonArreola \& Lopez-Vidal, 2004). In TB patients, high levels of anti-ManLAM Abs can be detected, making ManLAM a candidate for serological diagnosis (Hamasur et al., 2001). Indeed, a commercial kit, MycoDot, based on antibody recognition of the ManLAM is available (Hamasur et al., 2001). The main disadvantage of MycoDot is its low sensitivity (Ratanasuwan et al., 1997). Another disadvantage of using ManLAM for this test is the complex procedure required for its purification.

Due to its presence on the bacterial surface, ManLAM has also been suggested as a vaccine candidate (GlatmanFreedman et al., 2004). However, purified ManLAM, as other polysaccharides, is a poor immunogen (Hamasur et al., 1999) unless conjugated to a carrier protein (GlatmanFreedman et al., 2004). Peptide mimotopes of polysaccharides may be more efficient for elicitation of Abs than polysaccharides (Beninati \& Teti, 2000; Grothaus et al., 2000; Maitta et al., 2004; Prinz et al., 2004).

Therefore, in this work, we screened phage-display libraries in order to find ManLAM mimotopes. We describe here a peptide (B11) that is a ManLAM mimic.

\section{METHODS}

Materials. ManLAM from M. tuberculosis strain $\mathrm{H} 37 \mathrm{Rv}$ and nonmannose-capped lipoarabinomannan-binding mAb CS35 (Chatterjee et al., 1992; Kaur et al., 2002) and ManLAM-binding mAb CS40 (Chatterjee et al., 1992; Navoa et al., 2003) were kindly provided by Drs Brennan and Belisle (Colorado State University, Fort Collins, CO, USA; NIH grant AI-75320).

Peptide synthesis. Peptides were synthesized by Professor Fridkin at the Weizmann Institute, Rehovot, Israel, at the interdepartmental facility of the Hebrew University Faculty of Medicine, Jerusalem, Israel, and at Sigma (Rehovot, Israel) using a solid-phase technique. For conjugation to thiol-reactive keyhole limpet haemocyanin (KLH; Pierce), B11 peptide was synthesized with an additional N-terminal cysteine residue. $\mathrm{B} 11$ peptide, with or without cysteine, bound $\mathrm{mAb}$ CS40 in ELISAs.

Biopanning, phage screening assay and peptide sequencing. Random phage-display peptide libraries, constructed using the fth1 type 88 vector (Enshell-Seijffers et al., 2001), were biopanned as described previously (Enshell-Seijffers, 2002). Clones were screened for recognition by mAbs CS35 and CS40 using dot-blot analysis and analysed as described previously (Enshell-Seijffers et al., 2003).

Selected peptide sequence inserts were aligned by CLUSTAL $\mathrm{w}$ using MACVECTOR 7.0 (Oxford Molecular).

Direct ELISA. Direct ELISA tests were performed by coating 96-well ELISA plates overnight at $4{ }^{\circ} \mathrm{C}$ with $50 \mu \mathrm{l}$ per well of solutions containing either $10^{9}$ phages $\mathrm{ml}^{-1}, 5-20 \mu \mathrm{g}$ peptide $\mathrm{ml}^{-1}$ or $5 \mu \mathrm{g}$ ManLAM ml ${ }^{-1}$. Plates were washed twice in PBS and blocked with
$\mathrm{PBS} / 1 \%$ BSA. After washing twice in PBS, serum or $\mathrm{mAb}(50 \mu \mathrm{l}$ per well) was then added and incubated for $1 \mathrm{~h}$ at $37^{\circ} \mathrm{C}$. Plates were then washed four times. Alkaline phosphatase-labelled goat anti-mouse Ig (Sigma) was added for $90 \mathrm{~min}$ at $37{ }^{\circ} \mathrm{C}$, followed by $p$-nitrophenyl phosphate (KPL). The $A_{405}$ was measured using an ELISA reader (ELX-800UV; Bio-Tec Instruments). All samples were tested in triplicate.

For detection of IgM and IgG, sera were diluted $1: 50$ and $1: 200$ in PBS/0.5\% BSA. Human serum ELISA was performed according to Hetland et al. (1998). Sera were provided by Dr Spector (Hadassah University Hospital, Jerusalem, Israel), Professor Marchal (Pasteur Institute, Paris), Dr Acosta (Finlay Institute, Havana, Cuba) and Dr Mendez (Universita Veracruzana, Mexico) after appropriate Helsinki Committee approvals.

ELISA competition assay. An ELISA competition assay was performed according to Kaur et al. (2002). Briefly, Immulon 4HBX plates were coated with $50 \mu \mathrm{l}$ per well of a solution of $5 \mu \mathrm{g}$ ManLAM $\mathrm{ml}^{-1}$ and blocked as described above. mAb CS40 (diluted $1: 2000$ ) was mixed with various numbers $\left(0-1 \times 10^{16} \mathrm{ml}^{-1}\right)$ of phage particles in TBS/1\% BSA or various amounts $\left(0-200 \mu \mathrm{g} \mathrm{ml}{ }^{-1}\right)$ of synthetic peptide in $\mathrm{PBS} / 1 \% \mathrm{BSA}$. This solution was incubated for $60 \mathrm{~min}$ at room temperature and $50 \mu \mathrm{l}$ was transferred to the ELISA plates and incubated for $1 \mathrm{~h}$ at $37^{\circ} \mathrm{C}$. After washing in PBS, the ELISA procedure was performed as described above.

Surface plasmon resonance (SPR). Experiments were all performed using BIAcore 3000 at $30{ }^{\circ} \mathrm{C}$ in PBS (at a $20 \mu \mathrm{min}^{-1}$ flow rate). ManLAM was immobilized on a CM5 sensor chip according to the BIAcore aldehyde coupling protocol, using continuous flow $\left(5 \mu \mathrm{min}^{-1}\right)$. The surface was activated by $0.05 \mathrm{M}$ $\mathrm{N}$-hydroxysuccinimide and $0.2 \mathrm{M} N$-ethyl- $\mathrm{N}^{\prime}$-(dimethylaminopropyl)-carbodiimide and the introduction of a hydrazine group was done by injection of $5 \mathrm{mM}$ hydrazine, followed by deactivation of the unreacted esters by injection of $1 \mathrm{M}$ ethanolamine ( $\mathrm{pH} 8$ ). The ligand was injected at a concentration of $100 \mu \mathrm{g} \mathrm{ml}^{-1}$ in $10 \mathrm{mM}$ glycine buffer ( $\mathrm{pH}$ 1.5). The immobilization level was 400-600 resonance units. Stabilization of the bound ligand was done by injection of $0.1 \mathrm{M}$ cyanoborohydride in $0.1 \mathrm{M}$ acetate $(\mathrm{pH} 4)$ at $2 \mu \mathrm{min}^{-1}$. Activated Fc using the same procedure, without binding the ligand, served as a control. For evaluating the $K_{\mathrm{D}}$ of the mAb CS40-ManLAM interaction, different CS40 concentrations $(0-250 \mathrm{nM})$ were tested for binding of ManLAM. For evaluating the $K_{\mathrm{D}}$ of the mAb CS40-B11 peptide interaction, a competition assay (Montalto, 2001) was performed as follows. mAb CS40 $(125 \mathrm{nM})$ plus different concentrations of B11 peptide $(0-150 \mu \mathrm{M})$ were pre-incubated in PBS (30 min at $37^{\circ} \mathrm{C}$ ) and then injected manually over the cell flow. Comparative inhibition of $\mathrm{mAb}$ CS40 binding to ManLAM was evaluated, comparing B11 peptide with A1 peptide (Fig. 1) and B11-glycine, a control peptide synthesized with three glycine amino acids replacing the three aromatic amino acids $(\mathrm{W}, \mathrm{W}$ and $\mathrm{Y}$ ) of the B11 peptide

\begin{tabular}{ll} 
A1 & \multicolumn{1}{c}{ rcgWEADDKNQHGEGcaa } \\
B11 & rgISLTEWSMWYRHaa \\
C1 & rcgEEGPWSTHVGRTcaa \\
C3 & rgCWGNEGGDHLQPVCaa \\
F7 & rgSLKIRWELKMYQEcaa \\
G3 & rgCAVERWEKHTWSEcaa
\end{tabular}

Fig. 1. Phage-displayed peptides recognized by mAb CS40. Six peptide sequences (upper case) are given, flanked by residues derived from the fth 1 vector (lower case). Sequence inserts were aligned by CLUSTAL W using MACVECTOR 7.0. 
sequence (Fig. 1). A competition assay was performed as described above, by pre-incubating mAb CS40 $(250 \mathrm{nM})$ with $50 \mu \mathrm{M}$ of each of the peptides before injection.

Regeneration in all assays between each injection was done by injection of $10 \mu \mathrm{l} 1 \mathrm{mM} \mathrm{NaOH}$. BIAEVALUATION 4.0 (BIAcore) was used to calculate the $K_{\mathrm{D}}$ values using the solution-affinity model with general fit parameters.

Immunization protocols. Immunizations were all performed in specific-pathogen-free female BALB/c mice, $6-8$ weeks old. Five or $50 \mu \mathrm{g} \mathrm{KLH}$-conjugated peptide was administered twice at 3-week intervals subcutaneously (s.c.) and intraperitoneally (i.p.). The adjuvants monophosphoryl lipid A + trehalose dimycolate (MPL-TDM) (Sigma), incomplete Freund's adjuvant (Sigma) and dimethyldioctadecylammonium bromide (Fluka) were tested in s.c. immunization. Immunization i.p. was performed using the MPL-TDM adjuvant system (Sigma)

Control groups were immunized with KLH in the relevant adjuvant. For detection of serum-specific anti-ManLAM antibodies, mice were bled from the tail vein. All animal experiments were performed in accordance with the regulations of the animal experimentation ethics committee of the Hebrew University Hadassah Medical School.

Experimental M. tuberculosis infection. Specific-pathogen-free female BALB/c mice were inoculated intravenously in the tail vein with $5 \times 10^{5}$ c.f.u. of $M$. tuberculosis strain H37Rv (a kind gift from Professor Marchal, Pasteur Institute, Paris) (Hovav et al., 2003). Naïve mice $(n=6)$ and mice 30 days $(n=6)$ and 3 months $(n=4)$ after M. tuberculosis infection were bled and tested for the presence of IgG specific for ManLAM and B11 peptide.

Statistics analysis. Data were analysed by Student's $t$-test. $P$ values of $<0.05$ were considered to be significant.

\section{RESULTS AND DISCUSSION}

\section{Sequence selection by phage display technology}

mAb CS40 (Chatterjee et al., 1992; Navoa et al., 2003) and mAb CS35 (Chatterjee et al., 1992; Kaur et al., 2002) were used to screen the phage display libraries for ManLAM and non-mannose-capped lipoarabinomannan mimotopes, respectively, as described in Methods. Six different peptides were isolated using mAb CS40 (Fig. 1) but no relevant peptides were detected with $\mathrm{mAb}$ CS35. As in other carbohydrate mimotopes (Kieber-Emmons et al., 1999; Prinz et al., 2004; Young et al., 1997), tryptophan (W) is a conserved residue present in all selected sequences (Fig. 1). Among the sequences selected, B11 peptide was unique as it was the only peptide with three aromatic residues, which may be important in maintaining the peptide activity, even when produced synthetically and out of context of the phage. This propensity for multiple aromatics in highaffinity polysaccharide mimotopes has been reported previously by others (Park et al., 2004; Prinz et al., 2004; Westerink et al., 1995).

The relative efficiency of binding of the selected recombinant phage clones to mAb CS40 was performed by ELISA. The most efficient clone competing with ManLAM was B11 (data not shown). It has been shown previously that higher-affinity mimetics make mimotopes with better immunological characteristics (Fuchs et al., 2003; Young et al., 1997). Thus we examined the immunogenicity of the B11 phage clone. We found that mice immunized twice with the B11 phage clone developed specific ManLAM-binding IgG Abs (data not shown). Therefore, a synthetic sequence corresponding to the sequence present in the clone B11 was synthesized and tested for its binding and immunogenic properties.

\section{Binding properties of synthetic B11 peptide to mAb CS40}

To determine whether the B11 synthetic peptide was capable of binding $\mathrm{mAb}$ CS40 and inhibiting binding of $\mathrm{mAb}$ CS40 to the natural antigen ManLAM, we performed direct ELISAs, competitive ELISAs and SPR analysis. The binding properties of $\mathrm{B} 11$ were compared with those of two control peptides: (i) a sequence corresponding to clone A1 (Fig. 1), a phage clone that bound the $\mathrm{mAb}$ in direct ELISAs but did not compete in binding of mAb CS40 in competitive ELISAs, as described in Methods; and (ii) a control peptide, B11-glycine, designed to test the importance of the aromatic amino acids in binding to mAb CS40. B11-glycine peptide was synthesized with three glycine amino acids replacing the three aromatic amino acids ( $\mathrm{W}$, $\mathrm{W}$ and $\mathrm{Y}$ ) of the $\mathrm{B} 11$ peptide sequence. We found that the synthetic peptides (B11, A1 and B11-glycine) bound $\mathrm{mAb}$ CS40 in direct ELISAs (data not shown) with different efficiencies. However, in competitive ELISAs, only B11 competed with ManLAM in binding to the mAb ( $~ 90 \%$ decrease in $A_{405}$ with $50 \mu \mathrm{g}$ peptide $\mathrm{ml}^{-1}$ ). This reduction was not seen with the control peptide A1 (Fig. 2).

When evaluating the ability of the B11 peptide to inhibit binding of mAb CS40 to ManLAM in SPR comparative analysis, we found that B11 showed the highest inhibition of the three synthetic peptides (Fig. 3). For this assay, we primarily tested the binding of mAb CS40 to ManLAM. ManLAM was immobilized on a sensor chip and, as expected, mAb CS40 (250 nM) bound immobilized ManLAM (Fig. 3a). The inhibition of mAb CS40 binding to the immobilized ManLAM using B11 was compared with inhibition using the control peptides A1 and B11glycine (Fig. 3) using a competitive binding assay (Adamczyk et al., 2000; Montalto, 2001). For this, each of the three peptides $(50 \mu \mathrm{M}$ each) was pre-incubated with $\mathrm{mAb}$ CS40 for $30 \mathrm{~min}$ at $37^{\circ} \mathrm{C}$. After incubation, binding of free $\mathrm{mAb}$ to the immobilized ManLAM was measured and compared with binding of the $\mathrm{mAb}$ alone. All three peptides reduced binding of mAb CS40 to ManLAM, indicating that they bound the $\mathrm{mAb}$ (Fig. 3a). The highest inhibition was measured with the B11 peptide ( 60\%). The control peptides B11-glycine and Al had a lower inhibition of $\sim 30$ and $\sim 20 \%$, respectively (Fig. $3 \mathrm{~b}$ ). The comparative binding of B11 and B11-glycine indicated the importance of the aromatic amino acids in binding to $\mathrm{mAb}$ CS40. 


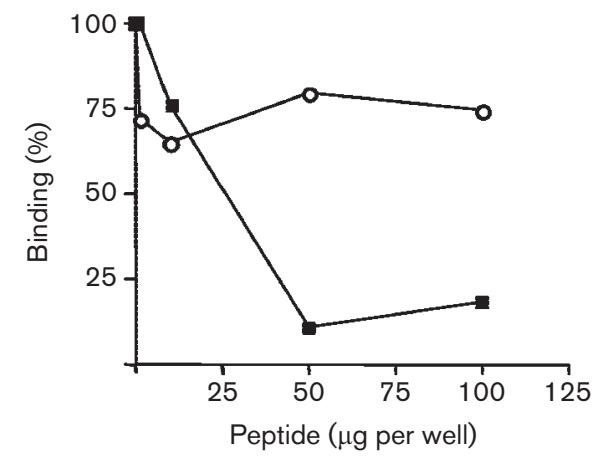

Fig. 2. Competitive binding of synthetic peptides against ManLAM by ELISA. Inhibition of mAb CS40 binding to ManLAM was analysed by incubating the antibody with increasing amounts of peptides B11 ( $\square)$ and A1 $(\bigcirc)$. Microtitre plate wells were coated with ManLAM ( $5 \mu \mathrm{g}$ per well). After blocking, mAb CS40 (diluted $1: 2000$ ) was added to wells with or without increasing amounts of peptide. Binding of mAb CS40 to ManLAM was detected using an alkaline phosphatase-conjugated secondary $\mathrm{Ab}$. The data represent the mean of triplicate wells. Binding of $100 \%$ was measured at an absorbance value of $0.2 \mathrm{~nm}$. Representative results shown are for one of three independent experiments.
These findings demonstrated that the synthetic B11 peptide specifically binds $\mathrm{mAb}$ CS40, indicating that B11 is a promising mimic of ManLAM.

\section{SPR determination of the affinity of synthetic B11 peptide to mAb CS40}

The affinity of the B11 peptide to mAb CS40 was measured by SPR analysis. For this evaluation, we first calculated the affinity of mAb CS40 to ManLAM (Fig. 4). Measuring the binding of $\mathrm{mAb}$ CS40 to immobilized ManLAM over a range of concentrations (0-250 nM) (Fig. 4a) enabled calculation of the $K_{\mathrm{D}}$ value $\left(3.00 \times 10^{-7}\right)$ (Fig. $4 \mathrm{~b}$ ), using BIAEVALUATION software version 4.0. As low-molecularmass analytes $(<1 \mathrm{kDa})$ do not give sizeable relative responses under direct binding conditions using BIAcore (Adamczyk et al., 2000; Montalto, 2001), we chose to calculate the affinity of B11 to mAb CS40 by solution competition experiments. For this, during the binding phase of the experiment, a solution of mAb CS40 or solutions of mAb CS40 plus different concentrations of B11 peptide were passed over the chip and the ability of B11 peptide to bind $\mathrm{mAb}$ CS40 was measured by the reduction
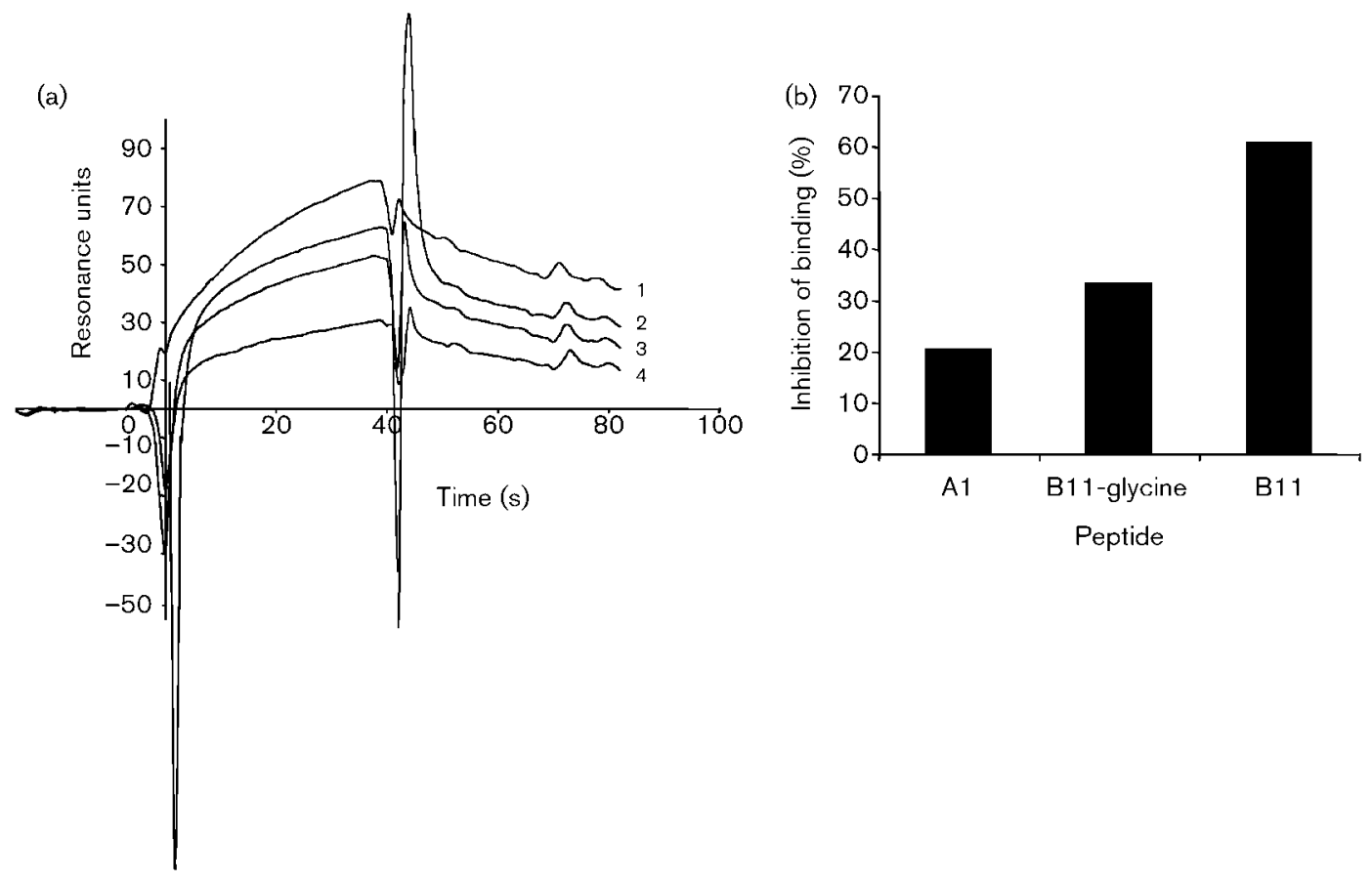

Fig. 3. Competitive binding of synthetic peptides against ManLAM by SPR analysis. The ability of B11 peptide to inhibit mAb CS40 binding to ManLAM was compared to that of the control peptides A1 and B11-glycine, as measured by competitive SPR analysis. (a) Binding of $\mathrm{mAb}$ CS40 alone $(1 ; 250 \mathrm{nM})$ to immobilized ManLAM was compared with the binding of $\mathrm{mAb}$ CS40 $(250 \mathrm{nM})$ after pre-incubation ( $30 \mathrm{~min}, 37^{\circ} \mathrm{C}$ ) with $50 \mu \mathrm{M}$ peptide $\mathrm{A} 1$ (2), B11-glycine (3) or B11 (4). Flow parameters and binding conditions are outlined in Methods. The results are shown as an overlay of the sensorgrams, zeroed on the $y$-axis to the mean baseline before injection. The start injection time for each sample was set to zero on the $x$-axis. (b) Percentage inhibition of mAb CS40 binding to ManLAM by B11 peptide and the control A1 and B11-glycine peptides, as calculated at the time of maximal binding (39 $\mathrm{s}$ after injection). 

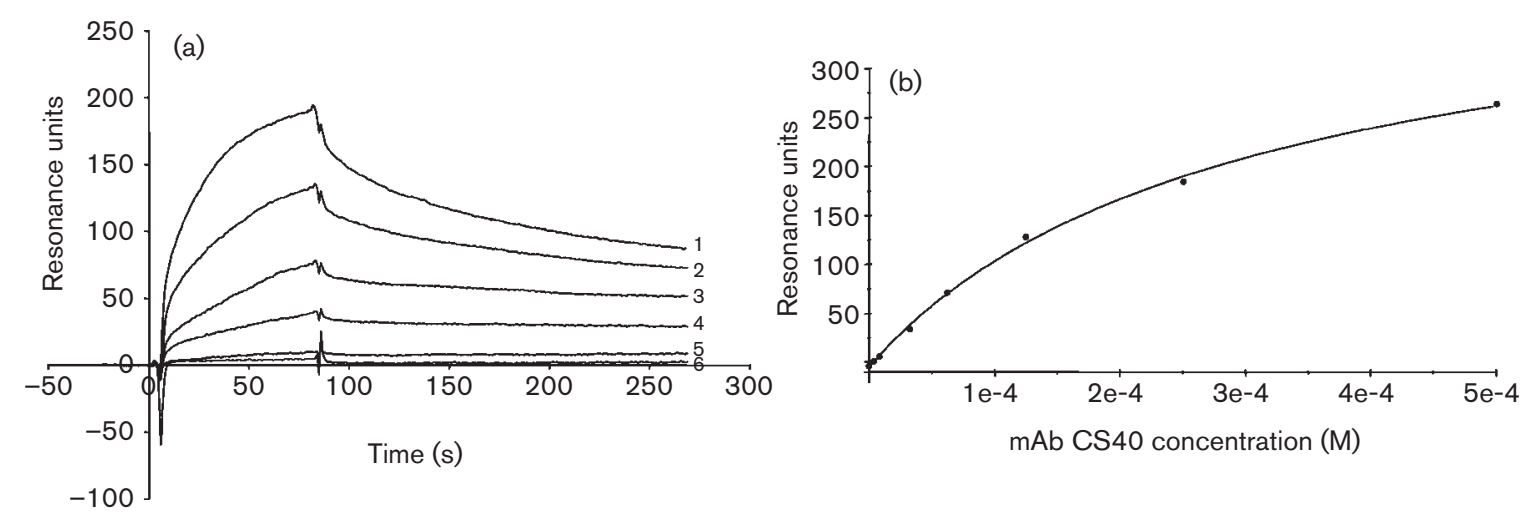

Fig. 4. SPR analysis of $m A b$ CS40 binding to ManLAM. SPR was performed at $30{ }^{\circ} \mathrm{C}$ as described in Methods. (a) Binding of a range of mAb CS40 concentrations [125 $\mu \mathrm{M}$ (1), $62.5 \mu \mathrm{M}$ (2), 31.25 $\mu \mathrm{M}$ (3), $7.8 \mu \mathrm{M}$ (4), $3.9 \mu \mathrm{M}$ (5) and $0 \mu \mathrm{M}$ (PBS only) (6)] to ManLAM, shown in an overlay of the sensorgrams, as described in the legend of Fig. 3 . Flow parameters and binding conditions are described in Methods. (b) Solution-affinity analysis of various mAb CS40 concentrations injected over immobilized ManLAM. The slope was recorded $76 \mathrm{~s}$ after injection. To generate the calibration curve, a non-linear regression plot of the initial binding rate was plotted using a four-parameter fit. The $K_{\mathrm{D}}$ of $3.00 \times 10^{-7}$ was established as described in Methods. Representative results shown are for one of three independent experiments.

in binding of mAb CS40 to ManLAM (Fig. 5a). The amount of mAb CS40 available to bind ManLAM was plotted against B11 peptide concentration (Fig. 5b). The $K_{\mathrm{D}}$ for the CS40-B11 interaction was determined to be $1.33 \times 10^{-8}$ using BIAEVALUATION software.

\section{Immunogenic properties of synthetic B11 peptide}

To test whether B11 synthetic peptide was a mimotope and thus induced ManLAM-binding IgG and IgM, mice $(n=5$ per group) were immunized with KLH-conjugated and non-conjugated peptide using various doses, routes of administration and adjuvants, as described in Methods. IgM and IgG ManLAM-binding Abs were detected only in the group immunized s.c. with $50 \mu \mathrm{g}$ conjugated peptide emulsified in MPL-TDM adjuvant. All groups showed high background levels of non-specific binding to ManLAM, as is commonly found in IgM ELISAs (Ochsenbein et al., 1999). Specific IgM was detected 2 weeks after the first injection ( $P<0.01$ vs the control groups) (Fig. 6a). IgG ( $P$ $<0.05$ vs the control groups) was detected 3 weeks after immunization (Fig. 6b). No Abs were detected in mice
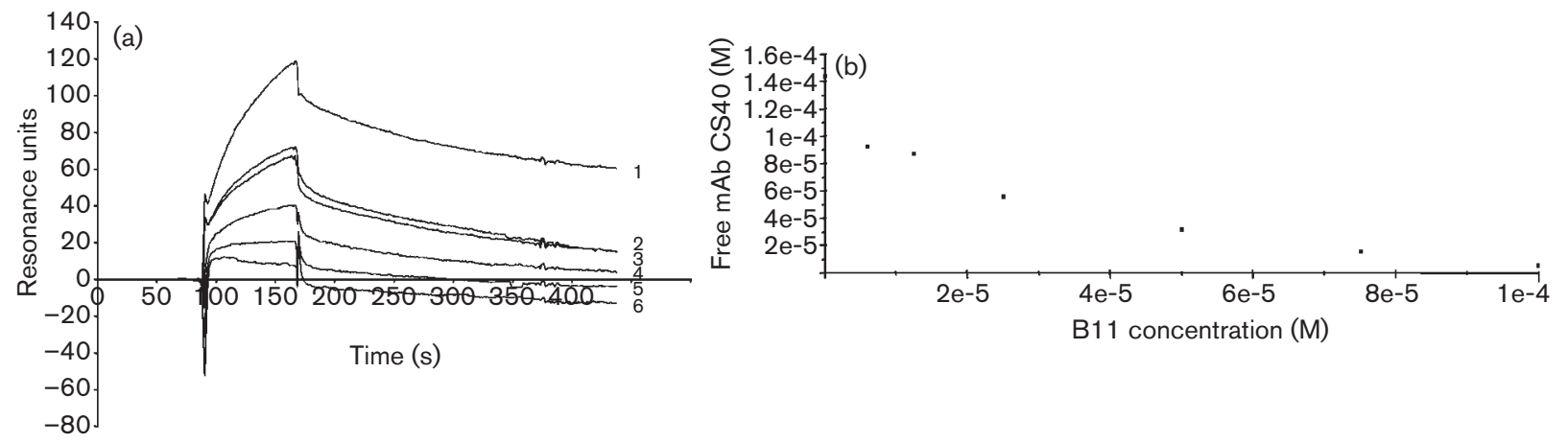

Fig. 5. Inhibition of binding of $m A b$ CS40 to ManLAM by B11 peptide. To measure the affinity of the mAb CS40 to B11 peptide, the inhibition of mAb CS40 binding to ManLAM by the B11 peptide was measured by SPR. (a) A range of B11 concentrations [0 $\mu \mathrm{M}$ (PBS only) (1), $6 \mu \mathrm{M}(2), 12.5 \mu \mathrm{M}$ (3), $25 \mu \mathrm{M}(4), 50 \mu \mathrm{M}$ (5) and $75 \mu \mathrm{M}$ (6)] were pre-incubated (30 min, $\left.37{ }^{\circ} \mathrm{C}\right)$ with $\mathrm{mAb}$ CS40 $(125 \mathrm{nM})$ before injection over immobilized ManLAM. Flow parameters and binding conditions are outlined in Methods. Sensorgrams were overlaid as described in the legend to Fig. 3. (b) To measure the mAb CS40-B11 interaction, the amount of free mAb CS40 in solution was determined from the calibration curve and plotted against B11 peptide concentrations. A $K_{\mathrm{D}}$ of $1.33 \times 10^{-8}$ was established as described in Methods. Representative results shown are for one of three independent experiments. 
(a)

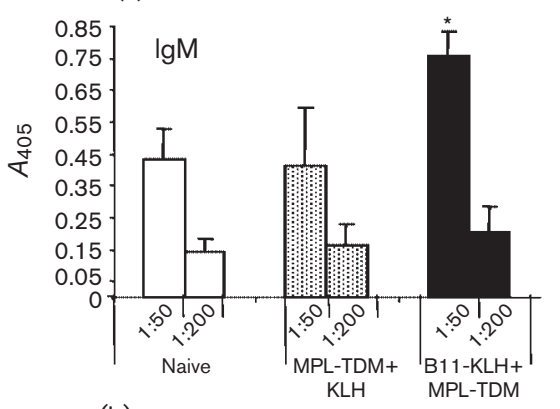

(b)

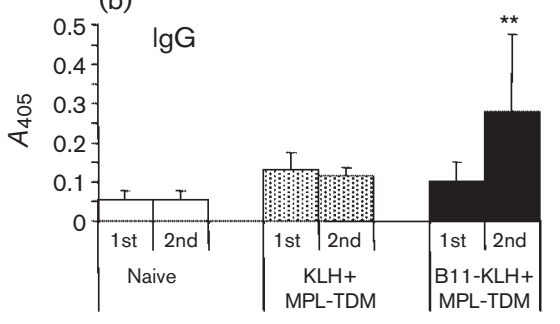

Fig. 6. Anti-ManLAM Ab titres in mice immunized with $B 11$ synthetic peptide. ManLAM-binding $\lg M(a)$ and $\lg G(b)$ in the sera of mice $(n=5)$ immunized twice ( $50 \mu \mathrm{g}$ per mouse) with $\mathrm{KLH}$ conjugated B11 peptide in MPL-TDM (filled bars) or with KLH in MPL-TDM as a control (dotted bars) or with saline (naïve mice, open bars) were detected by ELISA as described in Methods. In (a), levels of lgM titres are shown after the first immunization at two dilutions (1:50, $1: 200)$. In (b), lgG levels are shown after each immunization. Representative results shown are for one of three independent experiments. The $A_{405}$ value of each sample in triplicate was read $30 \mathrm{~min}$ after addition of substrate and the mean \pm SD was determined. Significance was determined by a one-tailed, unpaired Student's $t$-test: ${ }^{*}, P<0.01$; ${ }^{* *}, P<0.05$.

immunized with free B11 peptide, as has been described for other free peptides (Taouji et al., 2004; Wan et al., 2001) and peptide mimotopes (Charalambous \& Feavers, 2000). ManLAM-binding IgG was detected when mice were immunized s.c. with the conjugate in MPL-TDM adjuvant (50 $\mu \mathrm{g}$ per mouse), whereas no Abs were detected with the other adjuvants tested (incomplete Freund's adjuvant and dimethyldioctadecylammonium bromide i.p.). This correlates with results in the literature showing that administration of low-immunogenic synthetic peptides in MPL-TDM is more efficient by the s.c. route (Leenaars et al., 1998) and that administration of synthetic peptide in MPL-TDM adjuvant is more potent than administration in incomplete Freund's adjuvant (Honma et al., 1999).

\section{IgG B11 peptide-binding Abs in M. tuberculosis- infected mice}

To further evaluate the mimotope characteristics of the peptide, we compared the levels of Ab binding to B11 peptide with binding levels to ManLAM in the serum of mice experimentally infected with $M$. tuberculosis. Thirty days $(n=6)$ and 3 months $(n=4)$ after infection, both anti-ManLAM and B11 peptide-binding Abs were detected in the sera of $\mathrm{BALB} / \mathrm{c}$ mice. The levels of antibody binding to ManLAM and B11 peptide were similar (Fig. 7). B11-binding Abs increased 3 months post-infection compared with 1 month post-infection; this was also seen for anti-ManLAM Abs.

\section{IgG anti-peptide Abs in human TB patients}

TB patients develop high levels of anti-ManLAM Abs (Hamasur et al., 2001). Therefore, we used an ELISA to test whether the sera of $\mathrm{TB}$ patients contain Abs that can also bind B11 peptide. Similar to results found for ManLAM, we found significantly higher titres of B11 peptide-binding Abs in the sera of active pulmonary TB patients $(n=40)$ compared with the sera of healthy individuals $(n=36)$ (Fig. 8a). When defining a positive response as an $A_{405}$ value $+2 \mathrm{sD}$ higher than the mean for negative-control subjects, specificity $(\sim 90 \%)$ and sensitivity $(\sim 50 \%)$ were found to be similar to those described for the MycoDot kit (Ratanasuwan et al., 1997) (Fig. 8b). Twenty-one serum samples from the TB patients were positive for ManLAM and 20 were also positive for the B11 peptide, suggesting that the B11 peptide and ManLAM share a common epitope.

Using mimotopes for diagnosis has been suggested in a few studies such as that describing the polysaccharide mimotope of the Salmonella Vi antigen (Tang et al., 2003). Obtaining such mimotopes has rarely been successful (Youn et al., 2004). The results presented in this work

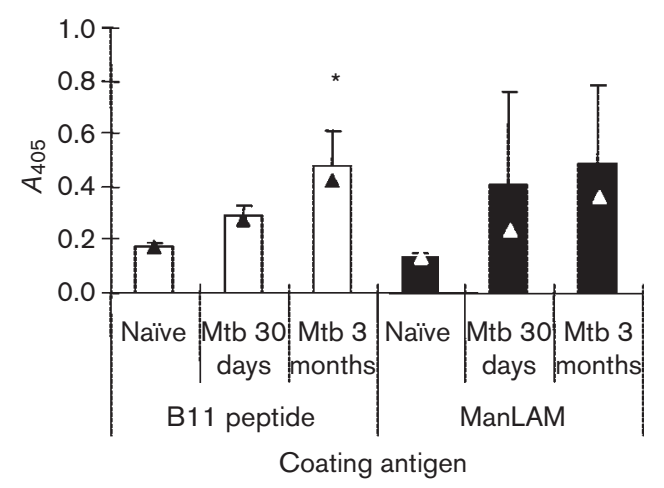

Fig. 7. Anti-ManLAM and B11-binding antibody titres in mice. Detection of serum $\lg$ in mice that bound ManLAM (filled bars) or B11 (open bars) was performed by ELISA. The plates were coated with $5 \mu \mathrm{g}$ ManLAM or B11 peptide per well, as described in Methods. Results are shown for naïve mice $(n=6)$ and $M$. tuberculosis (Mtb)-infected mice 30 days $(n=6)$ and 3 months $(n=4)$ post-infection. The median value is represented by a triangle. The $A_{405}$ value of each sample in triplicate was read 30 min after the addition of substrate and the mean \pm SD was determined. Significance was determined compared with the negative-control group by a one-tailed, unpaired Student's $t$-test: *, $P<0.01$. 
(a)

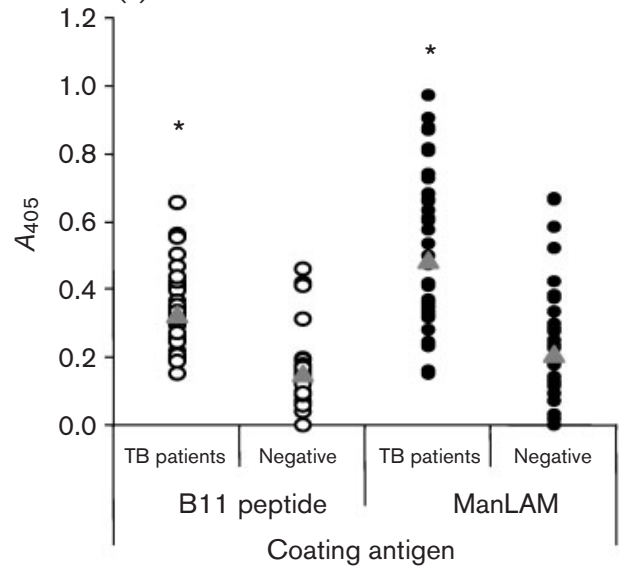

(b)

\begin{tabular}{|l|c|c|c|c|}
\hline Coating antigen & \multicolumn{2}{|c|}{ LAM } & \multicolumn{2}{c|}{ B11 } \\
\hline Response & + & - & + & - \\
\hline TB patients $(n=40)$ & 21 & 19 & 20 & 20 \\
\hline Healthy $(n=36)$ & 4 & 32 & 3 & 33 \\
\hline
\end{tabular}

Fig. 8. Anti-ManLAM and B11-binding antibody titres in human sera. (a) Detection of IgG in human sera that bound ManLAM (0) and B11 ( $\bigcirc)$ was performed by ELISA. The plates were coated with $5 \mu \mathrm{g}$ ManLAM or B11 peptide per well, as described in Methods. Sera from human healthy individuals $(n=36)$ and TB patients $(n=40)$ were tested. The median value is represented by a triangle. The results are shown as the mean $A_{405}$ value of each triplicate sample read $20 \mathrm{~min}$ after the addition of substrate. Significance was determined against the negative-control group by a one-tailed, unpaired Student's $t$-test. *, $P<0.0001$. (b) $A$ positive response was defined as an $A_{405}$ value $+2 \mathrm{SD}$ higher than the mean for negative-control subjects. The specificity was $91.6 \%$ for $\mathrm{B} 11$ and $88.8 \%$ for ManLAM, and the sensitivity was $50 \%$ for B11 and $52.5 \%$ for ManLAM. The SD values for the ManLAMcoated plates were 0.057 for the healthy individuals and 0.226 for the TB patients. The SD values for the B11 peptide-coated plates were 0.035 for the healthy individuals and 0.112 for the TB patients.

indicate the possibility of using the B11 mimotope in combination with a serological diagnosis kit. Using a peptide for this purpose has major benefits compared with the commonly used TB diagnostic tests. Serological diagnosis is rapid and requires only a single visit to the clinic, in contrast to clinical isolation of the slow-growing M. tuberculosis, which takes 3-4 weeks (Chan et al., 2000). A synthetic peptide can be inexpensive to produce, welldefined and highly reproducible (Shin et al., 2002), whilst purifying ManLAM from the virulent M. tuberculosis or from the bacillus Calmette-Guérin vaccine is a fastidious procedure. In addition, ManLAM from different batches may differ in antigenic properties.

Thus we conclude that the B11 peptide is an efficient and promising mimotope of ManLAM and shows potential for the clinical diagnosis of TB.

\section{ACKNOWLEDGEMENTS}

These studies were performed in the Peter A. Krueger P3 laboratory with the generous financial support of Nancy and Lawrence E. Glick. This work was supported in part by a grant from the Israeli Minister of Sciences and by a grant from the Center for the Study of Emerging Diseases.

\section{REFERENCES}

Adamczyk, M., Moore, J. A. \& Yu, Z. (2000). Application of surface plasmon resonance toward studies of low-molecular-weight antigenantibody binding interactions. Methods 20, 319-328.

Antunes, A., Nina, J. \& David, S. (2002). Serological screening for tuberculosis in the community: an evaluation of the Mycodot procedure in an African population with high HIV-2 prevalence (Republic of Guinea-Bissau). Res Microbiol 153, 301-305.

Beninati, C. \& Teti, G. (2000). A meeting of mimics. Trends Microbiol 8, 492-493.

Briken, V., Porcelli, S. A., Besra, G. S. \& Kremer, L. (2004). Mycobacterial lipoarabinomannan and related lipoglycans: from biogenesis to modulation of the immune response. Mol Microbiol 53, 391-403.

Castanon-Arreola, M. \& Lopez-Vidal, Y. (2004). A second-generation anti TB vaccine is long overdue. Ann Clin Microbiol Antimicrob 3, 10.

Chan, E. D., Heifets, L. \& Iseman, M. D. (2000). Immunologic diagnosis of tuberculosis: a review. Tuber Lung Dis 80, 131-140.

Charalambous, B. M. \& Feavers, I. M. (2000). Peptide mimics elicit antibody responses against the outer-membrane lipooligosaccharide of group B Neisseria meningitidis. FEMS Microbiol Lett 191, 45-50.

Chatterjee, D., Lowell, K., Rivoire, B., McNeil, M. R. \& Brennan, P. J. (1992). Lipoarabinomannan of Mycobacterium tuberculosis. Capping with mannosyl residues in some strains. J Biol Chem 267, 6234-6239.

Ciesielski, S. D. (1995). BCG vaccination and the PPD test: what the clinician needs to know. J Fam Pract 40, 76-80.

Enshell-Seijffers, D. J. G. (2002). Phage-display selection and analysis of Ab-binding epitopes. In Current Protocols in Immunology, unit 6.8, p. 9.8.1. Edited by J. E. Coligan, A. M. Kruisbeek, D. H. Margulies, E. M. Shevach \& W. Strober. New York: Wiley.

Enshell-Seijffers, D., Smelyanski, L. \& Gershoni, J. M. (2001). The rational design of a 'type 88 ' genetically stable peptide display vector in the filamentous bacteriophage fd. Nucleic Acids Res 29, E50.

Enshell-Seijffers, D., Denisov, D., Groisman, B., Smelyanski, L., Meyuhas, R., Gross, G., Denisova, G. \& Gershoni, J. M. (2003). The mapping and reconstitution of a conformational discontinuous B-cell epitope of HIV-1. J Mol Biol 334, 87-101.

Fuchs, S., Kasher, R., Balass, M., Scherf, T., Harel, M., Fridkin, M., Sussman, J. L. \& Katchalski-Katzir, E. (2003). The binding site of acetylcholine receptor: from synthetic peptides to solution and crystal structure. Ann N Y Acad Sci 998, 93-100.

Glatman-Freedman, A., Casadevall, A., Dai, Z., Jacobs, W. R., Jr, Li, A., Morris, S. L., Navoa, J. A., Piperdi, S., Robbins, J. B. \& other authors (2004). Antigenic evidence of prevalence and diversity of Mycobacterium tuberculosis arabinomannan. J Clin Microbiol 42, 3225-3231.

Grothaus, M. C., Srivastava, N., Smithson, S. L., Kieber-Emmons, T., Williams, D. B., Carlone, G. M. \& Westerink, M. A. (2000). Selection of an immunogenic peptide mimic of the capsular polysaccharide of Neisseria meningitidis serogroup A using a peptide display library. Vaccine 18, 1253-1263. 
Hamasur, B., Kallenius, G. \& Svenson, S. B. (1999). Synthesis and immunologic characterisation of Mycobacterium tuberculosis lipoarabinomannan specific oligosaccharide-protein conjugates. Vaccine 17, 2853-2861.

Hamasur, B., Bruchfeld, J., Haile, M., Pawlowski, A., Bjorvatn, B., Kallenius, G. \& Svenson, S. B. (2001). Rapid diagnosis of tuberculosis by detection of mycobacterial lipoarabinomannan in urine. $J$ Microbiol Methods 45, 41-52.

Hetland, G., Wiker, H. G., Hogasen, K., Hamasur, B., Svenson, S. B. \& Harboe, M. (1998). Involvement of antilipoarabinomannan antibodies in classical complement activation in tuberculosis. Clin Diagn Lab Immunol 5, 211-218.

Honma, K., Kato, T. \& Okuda, K. (1999). Salivary immunoglobulin A production against a synthetic oligopeptide antigen of Actinobacillus actinomycetemcomitans fimbriae. Oral Microbiol Immunol 14, 288-292.

Hovav, A. H., Mullerad, J., Davidovitch, L., Fishman, Y., Bigi, F., Cataldi, A. \& Bercovier, H. (2003). The Mycobacterium tuberculosis recombinant 27-kilodalton lipoprotein induces a strong Th1type immune response deleterious to protection. Infect Immun 71, 3146-3154.

Kaur, D., Lowary, T. L., Vissa, V. D., Crick, D. C. \& Brennan, P. J. (2002). Characterization of the epitope of anti-lipoarabinomannan antibodies as the terminal hexaarabinofuranosyl motif of mycobacterial arabinans. Microbiology 148, 3049-3057.

Kieber-Emmons, T., Luo, P., Qiu, J., Chang, T. Y., O, I., BlaszczykThurin, M. \& Steplewski, Z. (1999). Vaccination with carbohydrate peptide mimotopes promotes anti-tumor responses. Nat Biotechnol 17, 660-665.

Leenaars, M., Koedam, M. A., Hendriksen, C. F. \& Claassen, E. (1998). Immune responses and side effects of five different oil-based adjuvants in mice. Vet Immunol Immunopathol 61, 291-304.

Maitta, R. W., Datta, K., Lees, A., Belouski, S. S. \& Pirofski, L. A. (2004). Immunogenicity and efficacy of Cryptococcus neoformans capsular polysaccharide glucuronoxylomannan peptide mimotopeprotein conjugates in human immunoglobulin transgenic mice. Infect Immun 72, 196-208.

Montalto, M. C., Collard, C. D., Buras, J. A., Reenstra, W. R., McClaine, R., Gies, D. R., Rother, R. P. \& Stahl, G. L. (2001). A keratin peptide inhibits mannose-binding lectin. J Immunol 166, 4148-4153.

Navoa, J. A., Laal, S., Pirofski, L. A., McLean, G. R., Dai, Z., Robbins, J. B., Schneerson, R., Casadevall, A. \& Glatman-Freedman, A. (2003). Specificity and diversity of antibodies to Mycobacterium tuberculosis arabinomannan. Clin Diagn Lab Immunol 10, 88-94.

Ochsenbein, A. F., Fehr, T., Lutz, C., Suter, M., Brombacher, F., Hengartner, H. \& Zinkernagel, R. M. (1999). Control of early viral and bacterial distribution and disease by natural antibodies. Science 286, 2156-2159.
Park, I., Choi, I. H., Kim, S. J. \& Shin, J. S. (2004). Peptide mimotopes of Neisseria meningitidis group B capsular polysaccharide. Yonsei Med J 45, 755-758.

Prinz, D. M., Smithson, S. L. \& Westerink, M. A. (2004). Two different methods result in the selection of peptides that induce a protective antibody response to Neisseria meningitidis serogroup C. J Immunol Methods 285, 1-14.

Prinzis, S., Chatterjee, D. \& Brennan, P. J. (1993). Structure and antigenicity of lipoarabinomannan from Mycobacterium bovis BCG. $J$ Gen Microbiol 139, 2649-2658.

Ratanasuwan, W., Kreiss, J. K., Nolan, C. M., Schaeffler, B. A., Suwanagool, S., Tunsupasawasdikul, S., Chuchottaworn, C., Dejsomritrutai, W. \& Foy, H. M. (1997). Evaluation of the MycoDot test for the diagnosis of tuberculosis in HIV seropositive and seronegative patients. Int J Tuberc Lung Dis 1, 259-264.

Shin, J. S., Yu, J., Lin, J., Zhong, L., Bren, K. L. \& Nahm, M. H. (2002). Peptide mimotopes of pneumococcal capsular polysaccharide of $6 \mathrm{~B}$ serotype: a peptide mimotope can bind to two unrelated antibodies. $J$ Immunol 168, 6273-6278.

Tailleux, L., Schwartz, O., Herrmann, J. L., Pivert, E., Jackson, M., Amara, A., Legres, L., Dreher, D., Nicod, L. P. \& other authors (2003). DC-SIGN is the major Mycobacterium tuberculosis receptor on human dendritic cells. J Exp Med 197, 121-127.

Tang, S. S., Tan, W. S., Devi, S., Wang, L. F., Pang, T. \& Thong, K. L. (2003). Mimotopes of the Vi antigen of Salmonella enterica serovar typhi identified from phage display peptide library. Clin Diagn Lab Immunol 10, 1078-1084.

Taouji, S., Nomura, I., Giguere, S., Tomomitsu, S., Kakuda, T., Ganne, V. \& Takai, S. (2004). Immunogenicity of synthetic peptides representing linear B-cell epitopes of VapA of Rhodococcus equi. Vaccine 22, 1114-1123.

Wan, Y., Wu, Y., Bian, J., Wang, X. Z., Zhou, W., Jia, Z. C., Tan, Y. \& Zhou, L. (2001). Induction of hepatitis $B$ virus-specific cytotoxic $T$ lymphocytes response in vivo by filamentous phage display vaccine. Vaccine 19, 2918-2923.

Westerink, M. A., Giardina, P. C., Apicella, M. A. \& Kieber-Emmons, T. (1995). Peptide mimicry of the meningococcal group $C$ capsular polysaccharide. Proc Natl Acad Sci U S A 92, 4021-4025.

Youn, J. H., Myung, H. J., Liav, A., Chatterjee, D., Brennan, P. J., Choi, I. H., Cho, S. N. \& Shin, J. S. (2004). Production and characterization of peptide mimotopes of phenolic glycolipid-I of Mycobacterium leprae. FEMS Immunol Med Microbiol 41, 51-57.

Young, A. C., Valadon, P., Casadevall, A., Scharff, M. D. \& Sacchettini, J. C. (1997). The three-dimensional structures of a polysaccharide binding antibody to Cryptococcus neoformans and its complex with a peptide from a phage display library: implications for the identification of peptide mimotopes. J Mol Biol 274, 622-634. 